\title{
Inventário de movimentos de massa na bacia hidrográfica do rio Mascarada/RS
}

\author{
Mass movements inventory of the Mascarada river watershed/RS
}

\author{
Gabriel Lopes Cardozo' ${ }^{(1)}$, Franciele Zanandrea'(i), Gean Michel'(i), \\ Masato Kobiyama'(i)
}

'Instituto de Pesquisas Hidráulicas, Universidade Federal do Rio Grande do Sul, Porto Alegre, RS, Brasil

\section{RESUMO}

A criação de inventários de movimentos de massa é indispensável para o estudo da dinâmica de bacias hidrográficas. A alteração dessa dinâmica se dá no momento em que esses movimentos de massa são deflagrados, através do grande aporte inicial de sedimentos, e, ao longo do tempo, através da erosão superficial que ocorre devido a incidência de chuva nas cicatrizes dos movimentos de massa que ficaram com solo exposto. Assim, o presente estudo caracterizou os movimentos de massa ocorridos na bacia do rio Mascarada por meio de parâmetros geomorfológicos, como declividade e curvatura, e através da comparação de seus parâmetros de forma com diferentes métodos de obtenção de áreas de análise, sendo os parâmetros propostos Porcentagem de área afetada (PAA), Densidade de drenagem de cicatrizes $\left(D_{d c}\right)$ e Densidade de cicatrizes $\left(D_{\text {cic }}\right.$ ). Foram mapeadas 407 cicatrizes com uma área de $2,2 \mathrm{~km}^{2}$, declividade média de $36,1^{\circ}$ e todos ocorreram em regiões convergente-côncavas. A avaliação dos parâmetros mostrou que a área de influência representa melhor a magnitude dos escorregamentos ocorridos. Conclui-se que a elaboração de inventários de movimentos de massa com metodologias confiáveis pode fornecer informações importantes para o gerenciamento de desastres naturais.

Palavras-chave: Inventário; Escorregamentos; Hidrogeomorfologia

\section{ABSTRACT}

Mass movements inventories play a key role to the understanding of watershed dynamics. The alteration of this dynamics occurs in the moment of failure and after it due the erosion when precipitation hits the uncovered soil at the mass movement scars. Thus, this paper has characterized these mass movements, which are classified as landslides, occurred in Mascarada's river basin through different geomorphological parameters, as slope and curvature, and comparing shape parameters against different methodologies to determine the evaluation area. The proposed shape parameters Percentage of affected area $(P A A)$, Drainage density of scars ( $D_{\mathrm{dc}}$ ) and Density of scars ( $D_{\mathrm{cic}}$ ) were evaluated against total area of Mascarada's river basin, against two sub-basins and against a proposed "Area of influence". 407 scars were mapped with an area of $2,2 \mathrm{~km}^{2}$, a mean slope of $36,1^{\circ}$ and all scars are in convergent areas. The evaluation of shape forms showed 
that "area of influence" improved the understanding of this mass movements magnitude. Thus, the elaboration of mass movement inventories with reliable methodologies can provide important information for the natural disaster management.

Keywords: Inventory; Landslides; Hydrogeomorphology

\section{INTRODUÇÃO}

Os escorregamentos são eventos que afetam a sociedade em diferentes escalas temporais e espaciais, sendo que, grande parte da análise empregada para avaliar a ocorrência de movimentos de massa está ligada a ideia de que “o passado é a chave para o futuro". Assim, tal pensamento implica que é mais provável que os escorregamentos ocorram em locais onde já existem registros de ocorrência e, consequentemente, em locais com condições similares àquelas já afetadas (MURILLO-GARCÍA; ALCÁNTARA-AYALA, 2014).

Corroborando esse pensamento, Samia et al. (2017) apresentam o conceito de "path dependency" (dependência de caminho), onde demonstram que novos escorregamentos podem ser afetados por antigos escorregamentos. Desta maneira, a elaboração de inventários de escorregamentos tem um papel fundamental para o estudo desses fenômenos e, segundo Guzzetti et al. (2012), esses podem ser divididos de acordo com o propósito pelos quais são criados, sendo esses: (I) documentação da área afetada em bacias hidrográficas de diferentes escalas; (II) como etapa preliminar para a preparação de mapas de susceptibilidade, perigo e risco; (III) para a investigação das características geomorfológicas nas quais os escorregamentos ocorreram; e (IV) para o estudo da evolução da paisagem em lugares onde os escorregamentos dominam os processos sedimentológicos.

Em nível mundial, existem diferentes inventários e bancos de dados como o “EMDAT International Disaster Database", o "NASA Global Landslide Catalogue" e o "Global Fatal Landslide Database", porém seu uso deve ser comedido, uma vez que há estudos, como Kirschbaum et al. (2015), que mostram uma subestimação de escorregamentos ocorridos de cerda de 1400\% para o EM-DAT, devido a escala de análise. No Brasil não há um 
inventário nacional unificado e, sim, diferentes estudos realizados que buscaram criar inventários para determinados eventos, como Lopes et al. (2007b) e Bauzys (2012).

Froude e Petley (2018) afirmam que as regiões mais afetadas, no Brasil, estão nos arredores de São Paulo e Rio de Janeiro, ou seja, na região sudeste. Porém, há também um grande número de registros de movimentos de massa que ocorreram na região sul do Brasil. Entre tais eventos, pode-se citar o ocorrido na bacia hidrográfica do rio Mascarada no município de Rolante, no Rio Grande do Sul em 2017 (Zanandrea et al., 2018), objeto de estudo deste trabalho, o qual foi provocado por um volume de chuva excepcional e causou diversos danos de forma direta, como a inundação do município de Rolante, e indireta, como a interrupção do tratamento de água de cidades à jusante devido à alta turbidez da água.

De acordo com Smyth e Royle (2000) a realização de diagnósticos pós-desastre é essencial para a prevenção de desastres naturais, servindo como base para a gestão de risco. Assim, o presente estudo busca à elaboração do inventário e a caracterização geomorfométrica dos escorregamentos de terra e fluxo de detritos ocorridos na bacia do rio Mascarada em 2017. A partir disso, este inventário poderá servir na elaboração de mapas de perigo e de risco e auxiliar no entendimento da dinâmica de eventos extremos da bacia, melhorando o gerenciamento de desastres naturais da região.

\section{METODOLOGIA}

\section{1 Área de estudo}

A bacia hidrográfica do rio Mascarada está localizada no estado Rio Grande do Sul, e faz parte das cabeceiras da bacia hidrográfica do rio do Sinos. A bacia dos Sinos, localizada na porção nordeste do estado, possui uma área de aproximadamente 3.820 km² e população de cerca de 1,3 milhões de habitantes (IBGE, 2010), distribuídos em 32 munícipios (Figura 1). 
Figura 1 - Mapa de localização das bacias hidrográficas do rio Mascarada, Rolante e Sinos

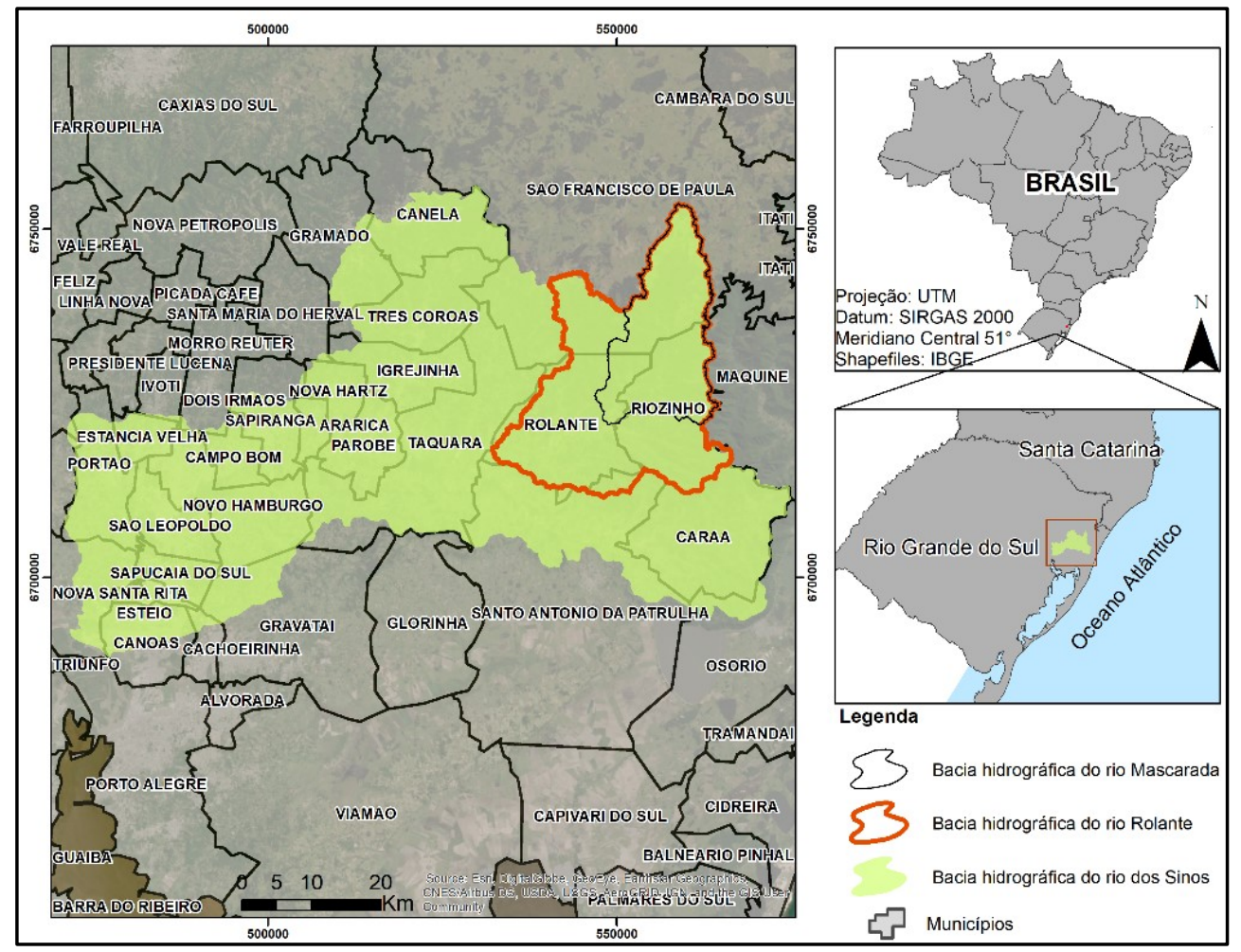

Fonte: Autores; Base cartográficas: IBGE, 2010

A bacia hidrográfica do rio Mascarada possui uma área de aproximadamente 320 $\mathrm{km}^{2}$, situada entre os munícipios de São Francisco de Paula, Riozinho e Rolante. Esta bacia é tributária do rio dos Sinos, no alto vale dos Sinos (Figura 1). Os municípios de São Francisco de Paula e Riozinho compõem as nascentes da bacia do rio Mascarada. As cabeceiras da bacia possuem vales e encostas escarpadas, encontrando planícies mais extensas nas áreas de jusante, onde se localiza a área urbana do município de Rolante.

A bacia hidrográfica do rio Mascarada, uma das cabeceiras do rio Rolante, possui altas declividades, chegando a apresentar inclinações próximas de 70 graus nas encostas. As altitudes na bacia variam de 66 a 996 m, com encostas declivosas e escarpadas (Figura 2) de solos rasos do tipo Neossolo Litólico apresentando baixas profundidades, em torno de 1 a $2 \mathrm{~m}$, com nuances de solos mais profundos (Dümig et al., 2008). A paisagem dissecada das escarpas em conjunto à baixa profundidade do solo proporciona seções transversais muito encaixadas do rio com declividade média 
de aproximadamente 37\%. A geologia da região, segundo Dantas, Viero e Silva (2010), caracteriza-se na transição das unidades do Planalto dos Campos Gerais, o qual é formado por derrames de rochas vulcânicas, e da Planície Litorânea do Rio Grande do Sul, a qual é formada por um conjunto variado de formas deposicionais, Ainda, segundo os autores, tais formações geológicas estão sujeitas a uma condição natural de instabilidade geomorfológica, tornando-as susceptíveis a movimentos de massa.

Figura 2 - Aspecto das encostas declivosas da bacia hidrográfica do rio Mascarada onde se observa exposto o manto rochoso deixado pelos escorregamentos e a ausência de planície de inundação na porção declivosa da bacia

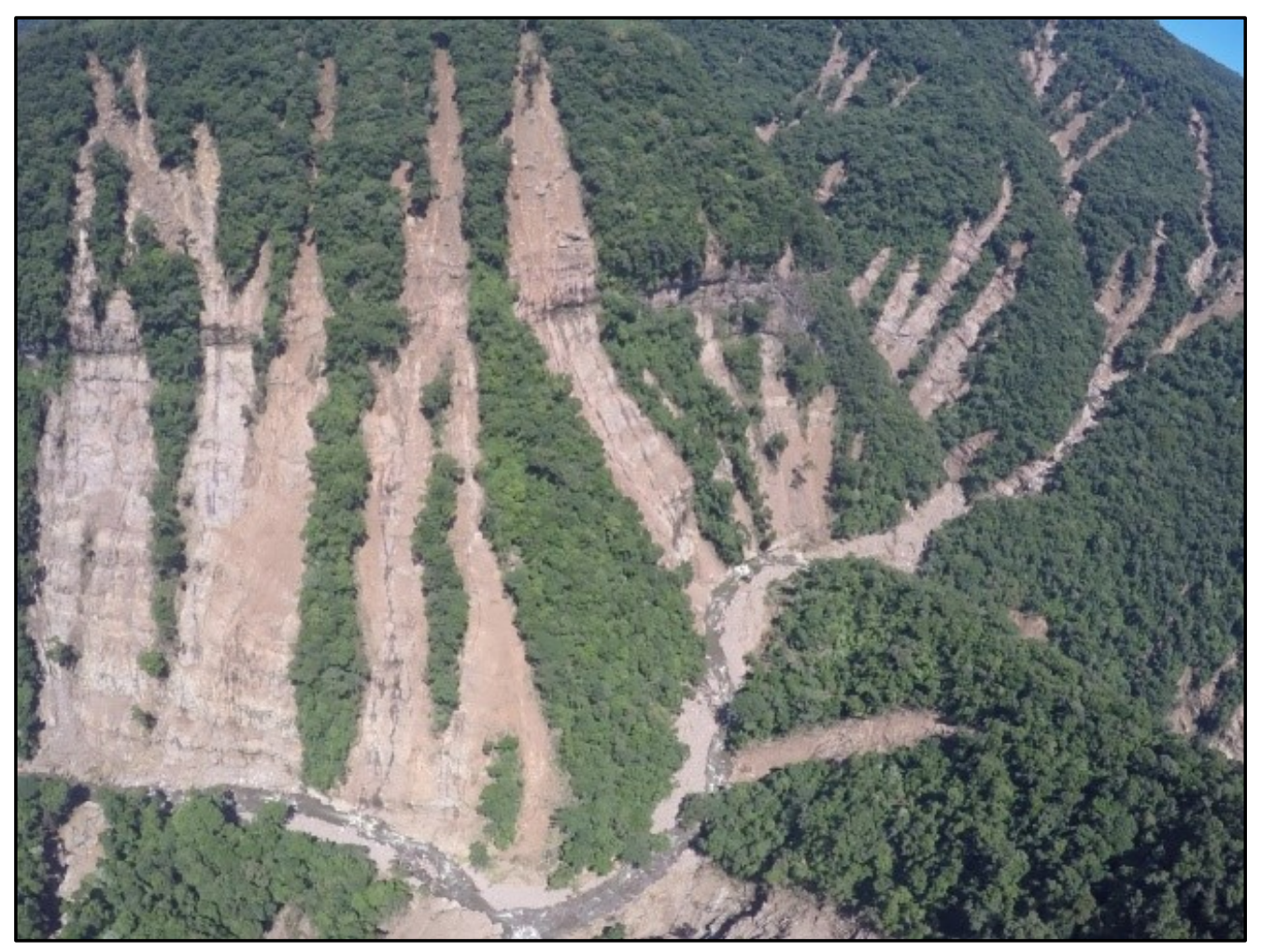

O Estado do Rio Grande do Sul possui precipitação média anual em torno de 1600 mm com boa distribuição espacial e temporal, porém a orografia ocasiona o aumento do movimento ascensional das massas de ar em alguns locais, o que pode ocasionar maiores volumes de chuva nas regiões montanhosas. A bacia do rio Mascarada, localizada na Serra do Nordeste do estado, possui uma maior incidência de chuva por estar localizada na 
parte alta do estado, atingindo valores anuais superiores a $2000 \mathrm{~mm}$ (GPDEN/SEMA, 2017). Essas chuvas podem desencadear desastres naturais (e.g. movimentos de massa e inundações), como os ocorridos na bacia em 2017.

\subsection{Descrição do evento de 2017}

Incidiram sobre as cabeceiras da bacia hidrográfica do rio Mascarada precipitações intensas no dia 5 de janeiro de 2017, que desencadearam centenas de escorregamentos de terra. Mesmo ocorrendo de forma concentrada apenas na porção superior da bacia, os efeitos deste desastre foram intensos no município de Rolante, localizado a jusante, atingido por uma inundação com alta concentração de sedimentos. Isso ocorreu, pois grande parte dos escorregamentos de terra alcançaram o canal e foram transportados até as regiões mais baixas da bacia. Essa inundação afetou em torno de 6,6 mil pessoas e 70\% do território do município, não ocorrendo óbitos de acordo com a prefeitura do município (ZANANDREA et al., 2018).

Até janeiro de 2017 não havia postos pluviométricos oficiais instalados na área afetada e, como estas chuvas ocorreram de forma concentrada, não existiam dados oficiais medidos do evento. Porém em levantamento realizado pelo GPDEN/SEMA (2017) pluviômetros não-oficiais caseiros de agricultores, localizados próximos ao local, mediram volumes variando entre $100 \mathrm{~mm}$ e $272 \mathrm{~mm}$ em poucas horas, enquanto que o pluviômetro oficial (Figura 3) mediu o volume de $66 \mathrm{~mm}$.

A partir dos dados do pluviômetro oficial foi obtida a média mensal para o mês de janeiro, que oscilou em torno de $180 \mathrm{~mm}$ acumulados. Segundo o levantamento realizado, existem evidências que o evento ocorreu devido à presença de sistemas de baixa pressão, associada ao relevo da região. Esse evento ocasionou também fortes modificações na morfologia do rio principal, além das vertentes afetadas (Figura 4 e Figura 5). 
Figura 3 - Altimetria e localização dos pluviômetros na bacia do rio Mascarada e suas subbacias. Área de influência dos escorregamentos utilizada na análise dos resultados.

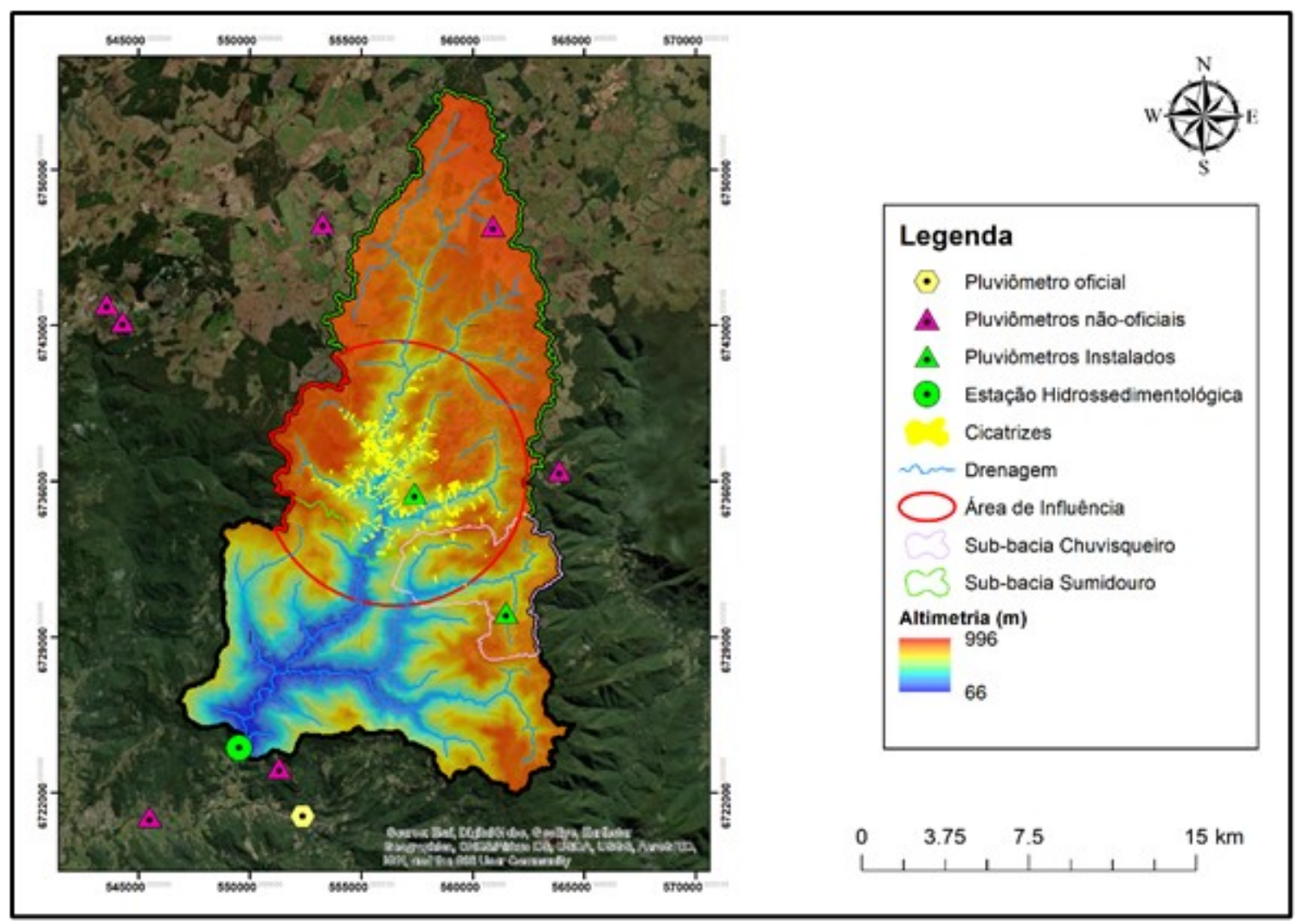

Fonte: autores

Figura 4 - Cicatrizes de escorregamentos de terra e fluxo de detritos ocasionados pelo evento de 2017 nas encostas da bacia do rio Mascarada/RS em a) 2017 e b) 2019. Em (b) é possível notar que a vegetação, após 2 anos, está avançando sobre o manto rochoso

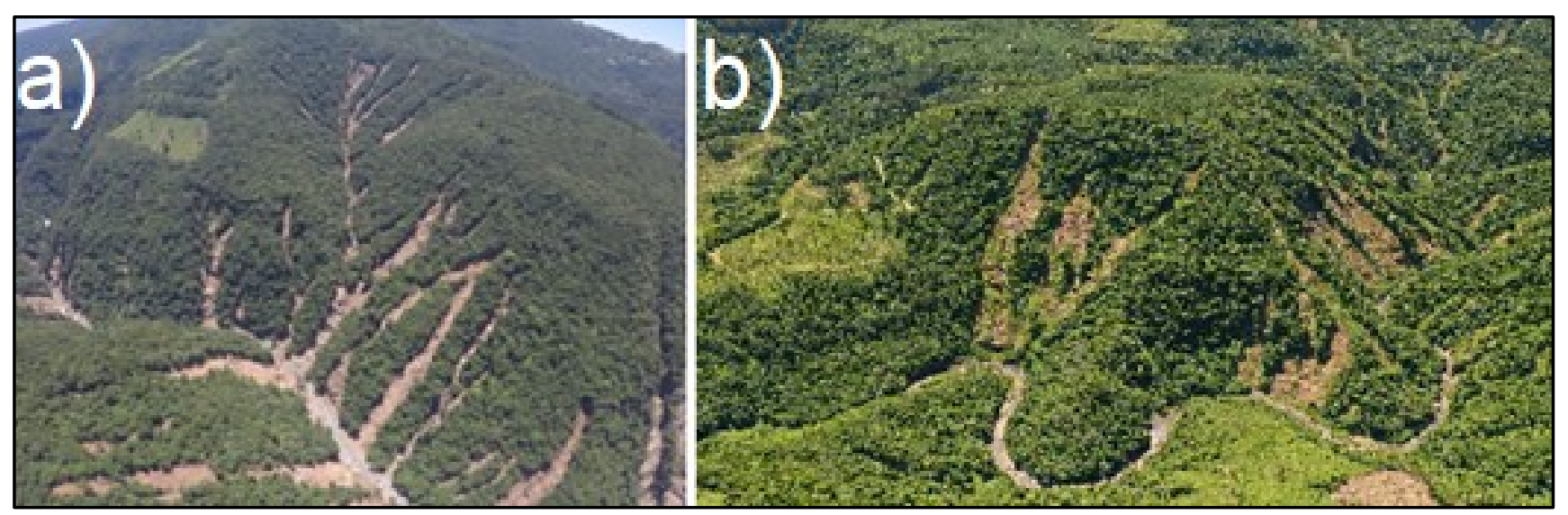

Fonte: Autores 
Figura 5 - Alterações na morfologia do canal principal da bacia do rio Mascarada/RS, onde observa-se a grande quantidade de sedimentos depositados alterando a morfologia do canal

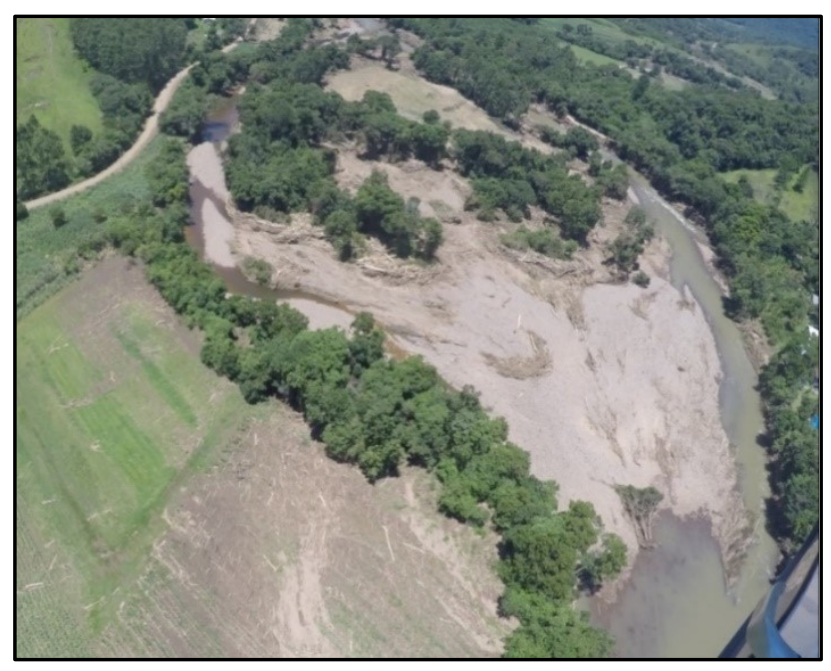

Fonte: Autores

Considerando a importância da área de estudo, foi implantado um sistema de monitoramento hidrossedimentológico na bacia, onde foi instalada uma estação hidrossedimentológico no exutório da bacia do rio Mascarada, a qual é composta por um sensor de nível, por um sensor de turbidez e por um pluviômetro, e outros dois pluviômetros nas cabeceiras, sendo que todos foram instalados pelo Grupo de Pesquisas em Desastres Naturais (GPDEN) do Instituto de Pesquisas Hidráulicas (IPH). A localização das estações, tanto dos agricultores como as instaladas posteriormente ao evento, encontram-se na Figura 3.

\subsection{Métodos}

As cicatrizes dos escorregamentos ocorridos no dia 05/01/2017 foram delimitadas a partir de imagens do satélite Sentinel-2 com resolução de 10 m (European Space Agency - ESA, 2015) do dia 15/01/2017. Através do uso de geoprocessamento delimitou-se a área dos escorregamentos, sendo que, não foram distinguidas áreas de ruptura, transporte e 
deposição de cada escorregamento, sendo apenas excluídas as áreas de transporte de sedimento pelo rio.

As análises geomorfológicas foram realizadas a partir do Modelo Digital de Terreno (MDT) AW3D com 1 metro de resolução, adquirido da NTT DATA Corporation, o qual foi gerado através da combinação de múltiplas imagens de alta resolução obtidas com a constelação de satélites DigitalGlobe. As cicatrizes foram avaliadas em comparação com diferentes sub-bacias, sendo essas denominadas de Sumidouro e Chuvisqueiro, de acordo com os dois principais rios que compõem a bacia do rio Mascarada (Figura 3). Os exutórios foram definidos de maneira que a área de contribuição desses englobasse a área das cicatrizes e, ainda, que a área de contribuição fosse a menor possível.

As cicatrizes também foram avaliadas de acordo com a área de influência, definida por Zanandrea et al. (2018). Esta área foi estabelecida criando um círculo cujo raio é definido através da distância entre o centro geométrico das cicatrizes e o vértice mais longínquo das cicatrizes, além disso, esse círculo tem seus limites definidos dentro da bacia hidrográfica, delimitando então a chamada "área de influência".

O comprimento das cicatrizes foi determinado de maneira semelhante ao usado por Roback et al. (2018). Como as cicatrizes possuem formato alongado, delgado e retilíneos, aproxima-se ao comprimento pelo lado equivalente dos polígonos que as cicatrizes geram (ROBACK et al., 2018). Porém como as formas nas cicatrizes da bacia do rio Mascarada não são retilíneas, ou seja, apresentam sinuosidades, o uso desse método subestimaria o comprimento. Assim, para considerar esse efeito adotou-se como comprimento da cicatriz a metade do perímetro do polígono que delimita a cicatriz, visto que, dessa forma, as características sinuosas das cicatrizes são compensadas (ZANANDREA et al., 2018).

As declividades e a curvatura das encostas foram geradas a partir do MDT com o uso do software ArcGis. Estes dados foram cruzados com a área das cicatrizes, obtendo então a declividade e a curvatura das áreas onde ocorreram os escorregamentos. Para essa análise foram consideradas apenas as áreas dos escorregamentos, ou seja, quando 
dois escorregamentos seguem o mesmo caminho esses passam a ser considerados fluxo de detritos. Também foram classificadas as drenagens da bacia de acordo com a hierarquização fluvial de Strahler (1957) incluindo a ordem zero, proposta por Tsukamoto e\& Minematsu (1987). Assim, avaliou-se a ordem da drenagem onde iniciaram e onde chegaram as cicatrizes de escorregamento.

A partir das variáveis geradas foram calculados os seguintes parâmetros: a porcentagem de área atingida (PAA), a densidade de drenagem de cicatrizes $\left(\mathrm{km} / \mathrm{km}^{2}\right)\left(\mathrm{D}_{\mathrm{dc}}\right)$, e a densidade de cicatrizes $\left(\mathrm{N}^{\circ} / \mathrm{km}^{2}\right)\left(\mathrm{D}_{\mathrm{cic}}\right)$ :

$$
\begin{aligned}
P A A & =\frac{\sum A_{c i c}}{A_{\text {sub }}} * 100 \\
D d_{c} & =\frac{\sum L_{c i c}}{A_{\text {sub }}} \\
D_{\text {cic }} & =\frac{\sum N_{\text {cic }}}{A_{\text {sub }}}
\end{aligned}
$$

onde $A_{c i c}$ é a área atingida pelas cicatrizes $\left(\mathrm{km}^{2}\right) ; A_{\text {sub }}$ é a área total da sub-bacia $\left(\mathrm{km}^{2}\right) ; L_{c i c}$ é o comprimento das cicatrizes $(\mathrm{km})$; e $N_{c i c}$ é o número de cicatrizes. Esses índices foram calculados também em relação a área de influência $\left(A_{\text {inf }}\right)$.

O uso do solo foi analisado através da imagem do satélite Sentinel-2 do dia 06/12/16, com 10 metros de resolução. Com auxílio do software ArcGis a área da bacia do Mascarada foi dividida em oito diferentes classes de uso do solo: Estradas de terra; Urbanização; Floresta; Pasto; Agricultura; Solo exposto; Rios e Lagos. Ainda com auxílio do software foi calculado o "Topographic Wetness Index" (TWI), descrito por Kalantari et al. (2019):

$$
T W I=\ln \frac{A c c * 2}{\tan \varnothing}
$$

Onde Acc é a área de contribuição de cada pixel $\left(\mathrm{m}^{2}\right)$ e $\emptyset$ é a declividade do pixel $\left(^{\circ}\right)$.

Pontos aleatórios foram distribuídos ao longo da bacia do rio Mascarada para efeitos de comparação dos valores dos parâmetros topográficos, sendo eles declividade e TWI, com pontos 
nos centroides e no início das cicatrizes de escorregamento e valores médios de cada cicatriz. Para a avaliação estatística entre os valores foi utilizado o teste ANOVA, visto que esse permite verificar se há diferença significativa entre os grupos analisados, segundo Paolella (2018).

A área de contribuição de cada escorregamento foi obtida através da ferramenta "flowaccumulation" do software ArcGis. Para isso, foi selecionado o vértice mais a montante da encosta de cada cicatriz e, a partir desse, foi feito um buffer de 30 metros, delimitado pela área da cicatriz, assim, o maior valor contido nessa área foi adotado como a área de contribuição do escorregamento. Os dados de declividade e área de contribuição foram utilizados para a comparação das características do inventário gerado com as proposições feitas por Montgomery e Dietrich (1994) acerca da zona de iniciação de escorregamentos.

\section{RESULTADOS E DISCUSSÕES}

Através das imagens de satélite mapeou-se um total de 407 cicatrizes, sendo que 356 são cabeceiras, ou seja, escorregamentos e as 51 restantes são de fluxo de detritos, com uma área total de aproximadamente $2,2 \mathrm{~km}^{2}$. Em trabalhos de campo foram encontradas cicatrizes de escorregamentos de menor tamanho, ao quais não podem ser identificadas por imagens de satélite devido a vegetação densa da região e a resolução das imagens disponíveis, assim, a área diretamente afetada pode ser ainda maior. As áreas afetadas tiveram a cobertura e parte do seu solo removido, favorecendo os processos erosivos, apresentando também alguns locais com rocha exposta. Essa condição pode aumentar a distribuição de frequência e magnitude de eventos de produção de sedimentos em suspensão por anos se as cicatrizes de escorregamentos e caminhos do fluxo permanecerem sem vegetação (HICKS; GOMEZ; TRUSTRUM, 2000).

A área dos escorregamentos representou 0,59\% (Tabela 1) da área da bacia do rio Mascarada, porém os efeitos indiretos desses escorregamentos, como a inundação com alta concentração de sedimentos, foram sentidos ao longo de toda a bacia do rio dos Sinos (Figura 1). GPDEN/SEMA (2017) relataram que em janeiro de 2017, ocorreu a interrupção do sistema de 
abastecimento de água nos municípios do Baixo Sinos, devido à alta turbidez da água ocasionada pelos escorregamentos nas cabeceiras.

Na Tabela 1 são apresentados os valores dos parâmetros calculados em relação às diferentes regiões avaliadas, bem como a sua área e o número de escorregamentos que ocorreram dentro dessas. Através dos valores dos parâmetros nota-se que a metodologia adotada para definir a região afetada tem grande efeito na interpretação dos resultados.

Os valores de $D_{\text {cic }}\left(N^{\circ} / \mathrm{km}^{2}\right)$ (Tabela 1) se mostraram relativamente elevados para a área de influência, demonstrando assim a magnitude do evento que causou visíveis alterações na paisagem (Figuras 4 e 5). A avaliação da densidade de drenagem de cicatrizes mostra que, para a sub-bacia do Sumidouro e para a área de influência, os valores seriam considerados como drenagem regular quando comparados aos valores utilizados por Gregory e Walling (1968). Esta classificação é aplicada para rios, porém os valores deste trabalho foram obtidos apenas com dados de escorregamentos, salientando, assim, a grande magnitude do evento ocorrido. Ou seja, considerando um cenário hipotético onde antes dos escorregamentos não havia drenagem na área de estudo, apenas um evento de movimentos de massa foi capaz de gerar uma densidade de drenagem similar ao de uma paisagem com drenagem regular. Considerando outro cenário hipotético, onde a densidade de drenagem na bacia já era regular antes da ocorrência dos escorregamentos, têm-se os escorregamentos ocorrendo por toda a drenagem da bacia.

Tabela 1 - Número de cicatrizes, Área, Porcentagem de área atingida (PAA), Densidade de drenagem de cicatrizes $\left(D_{d c}\right)$, e Densidade de cicatrizes $\left(D_{\text {cic }}\right)$ para as áreas de avaliação

\begin{tabular}{|c|c|c|c|c|c|}
\hline Área de avaliação & Cicatrizes & Área $\left(\mathrm{km}^{2}\right)$ & PAA (\%) & $D_{\text {cic }}\left(N^{\circ} / \mathrm{km}^{2}\right)$ & $D_{d c}\left(k m / k^{2}\right)$ \\
\hline Bacia do Mascarada & 407 & 311,18 & 0,59 & 1,31 & 0,22 \\
\hline Sub-bacia Sumidouro & 395 & 160,08 & 1,12 & 2,47 & 0,40 \\
\hline Sub-bacia Chuvisqueiro & 12 & 27,45 & 0,19 & 0,44 & 0,08 \\
\hline Área de Influência & 407 & 110,93 & 1,67 & 3,67 & 0,60 \\
\hline
\end{tabular}

A comparação dos valores entre a bacia do Mascarada e suas sub-bacias afetadas, excluindo a área de influência, demonstrou maiores valores para a sub-bacia do Sumidouro onde ocorreram a grande maioria dos escorregamentos. Porém, quando a comparação inclui 
a área de influência, os maiores valores são encontrados para essa área, uma vez que a utilização dessa metodologia evita que áreas de montante que não foram afetadas direta ou indiretamente sejam consideradas nos cálculos, como observado por Zanandrea et al. (2018).

Os efeitos indiretos dos escorregamentos foram provocados pela alta quantidade de sedimentos mobilizados para o canal de drenagem, assim, para melhor entendimento do alcance dos escorregamentos, classificou-se os escorregamentos como estando conectados ou não-conectados ao canal (Figura 6). Os escorregamentos conectados tiveram seus depósitos majoritariamente carreados pela grande vazão gerada durante o evento chuvoso e os escorregamentos não-conectados depositaram-se ao longo da encosta. Considerando a profundidade média do solo observada em campo na bacia igual a 1 metro, representado pelo "h" na Figura 7 foi feita uma estimativa do volume de sedimentos que chegou até o canal. Assim, como 303 escorregamentos alcançaram o canal, estando classificados como conectados (Figura 6), representando uma área de 1,83 milhões de $\mathrm{m}^{2}$, estima-se que em torno de 1,83 milhões de $\mathrm{m}^{3}$ alcançaram a rede de drenagem durante o evento, o que ocasionou a inundação com alta concentração de sedimentos a jusante.

Figura 6 - Escorregamentos conectados e não-conectados à rede de drenagem

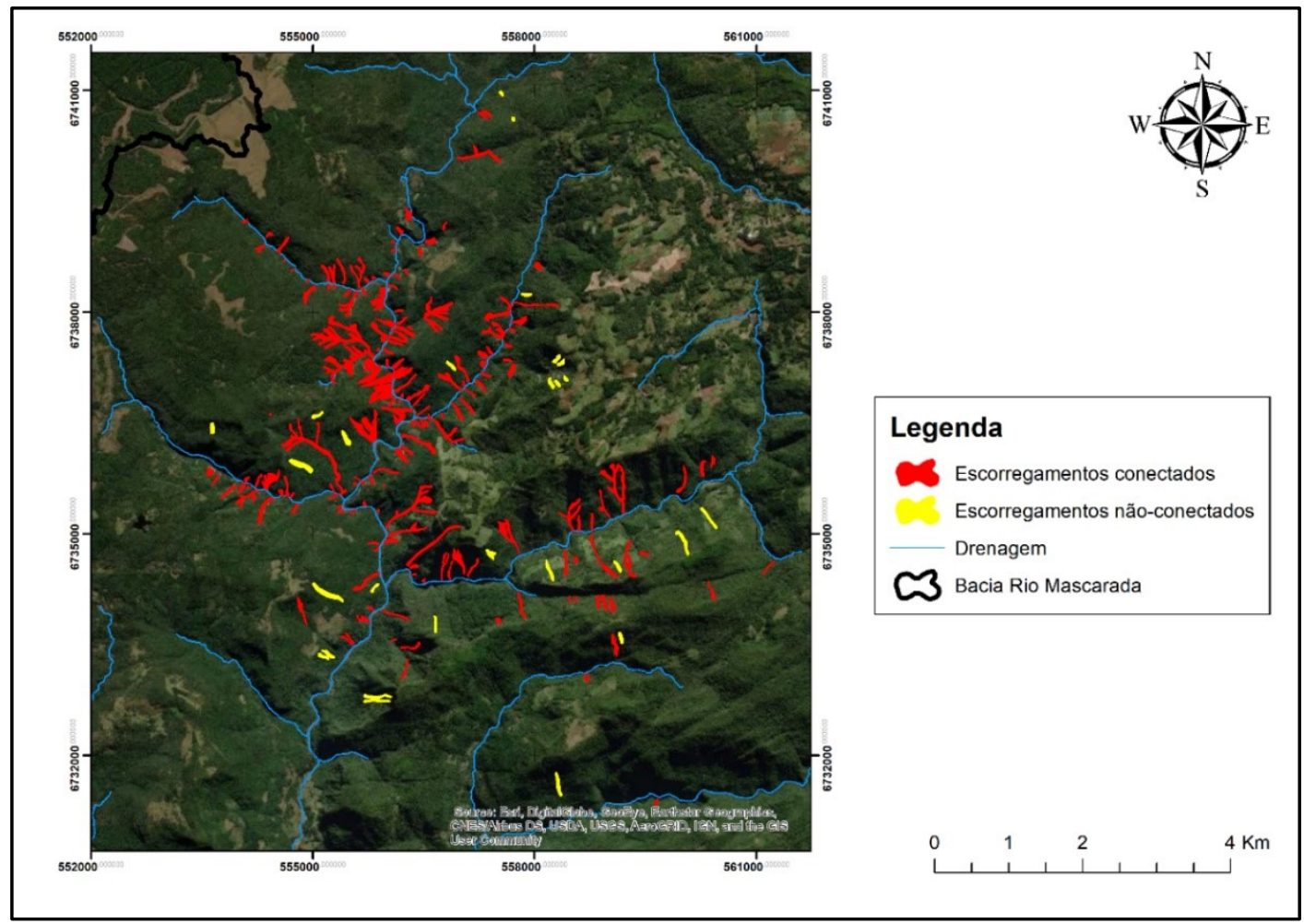


Fonte: Autores

Figura 7 - Profundidade média dos escorregamentos de terra na bacia do rio Mascarada

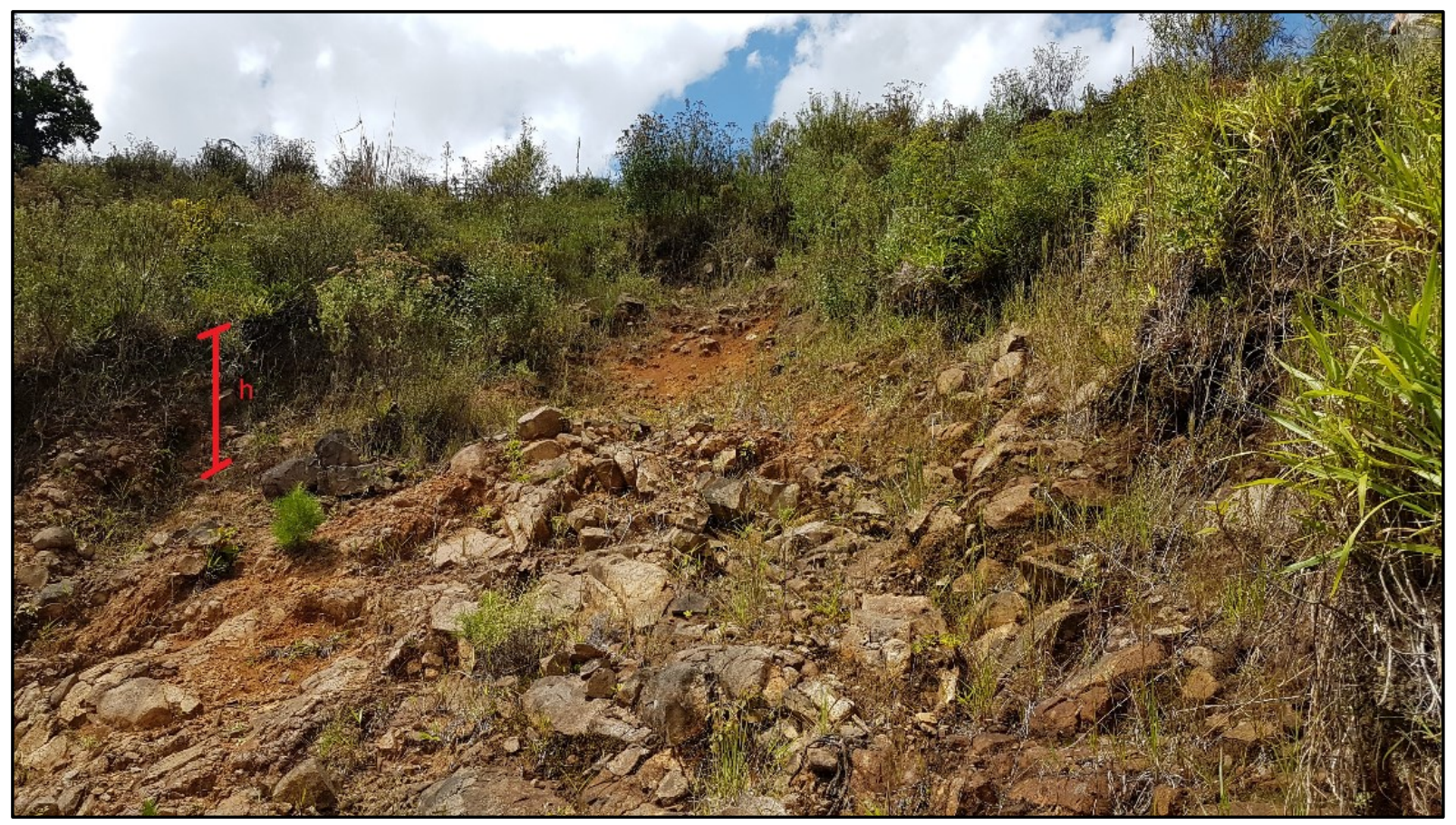

Fonte: Autores

A Tabela 2 apresenta os valores de declividade divididos em quatro categorias entre os valores de $15^{\circ}$ a $65^{\circ}$ encontrados para os escorregamentos mapeados na região. Além disso são apresentados o número de escorregamentos em cada categoria e seu percentual relativo ao total deflagrado. A declividade ao longo da bacia é apresentada na Figura 8.

A grande maioria dos escorregamentos está entre as declividades de 25 e $45^{\circ}$ (Tabela 2) e somente $12.43 \%$ nas maiores declividades, sendo que a declividade média dos escorregamentos é de $36,01^{\circ}$. O valor médio da declividade é compatível com outros inventários feitos no Brasil, como apresentado Lopes et al.(2007a, 2007b), no estado de São Paulo, e Seefelder, Koide e Mergili (2017), no estado do Rio de Janeiro, onde as declividades médias dos estudos foram aproximadamente $35^{\circ}$. Porém se comparado com trabalhos no Japão, como Iwahashi, Watanabe e Furuya (2001) e Iwahashi, Watanabe e Furuya (2003), e com o trabalho de Avelar (2013), que inventariou os escorregamentos ocorridos em Nova Friburgo no Rio de Janeiro, os valores foram superiores, uma vez que as médias apresentadas pelos autores para ambos os trabalhos são menores do que $20^{\circ}$. Assim, fica evidente a necessidade 
da criação de inventários em regiões com características, como clima e geomorfologia, semelhantes para que comparações possam ser feitas, pois existem poucos inventários publicados.

Todas as classes apresentadas podem ser consideradas como encostas declivosas, fato que favorece que os escorregamentos se tornem fluxos de detritos e cheguem ao canal. Outra característica topográfica que colaborou para a chegada de muitos escorregamentos ao canal é a curvatura convergente-côncava a qual representa 100\% dos escorregamentos, o que corrobora a teoria de Montgomery e Dietrich (1994) de que os escorregamentos translacionais rasos são deflagrados a partir da convergência de escoamento. Entretanto deve-se levar em consideração que o MDT foi obtido após os escorregamentos, assim, as cicatrizes na paisagem geradas pelos escorregamentos podem ter influenciado esse resultado.

Figura 8 - Mapa de declividade da bacia hidrográfica do rio Mascarada e identificação das cicatrizes deixadas pelos escorregamentos de terra

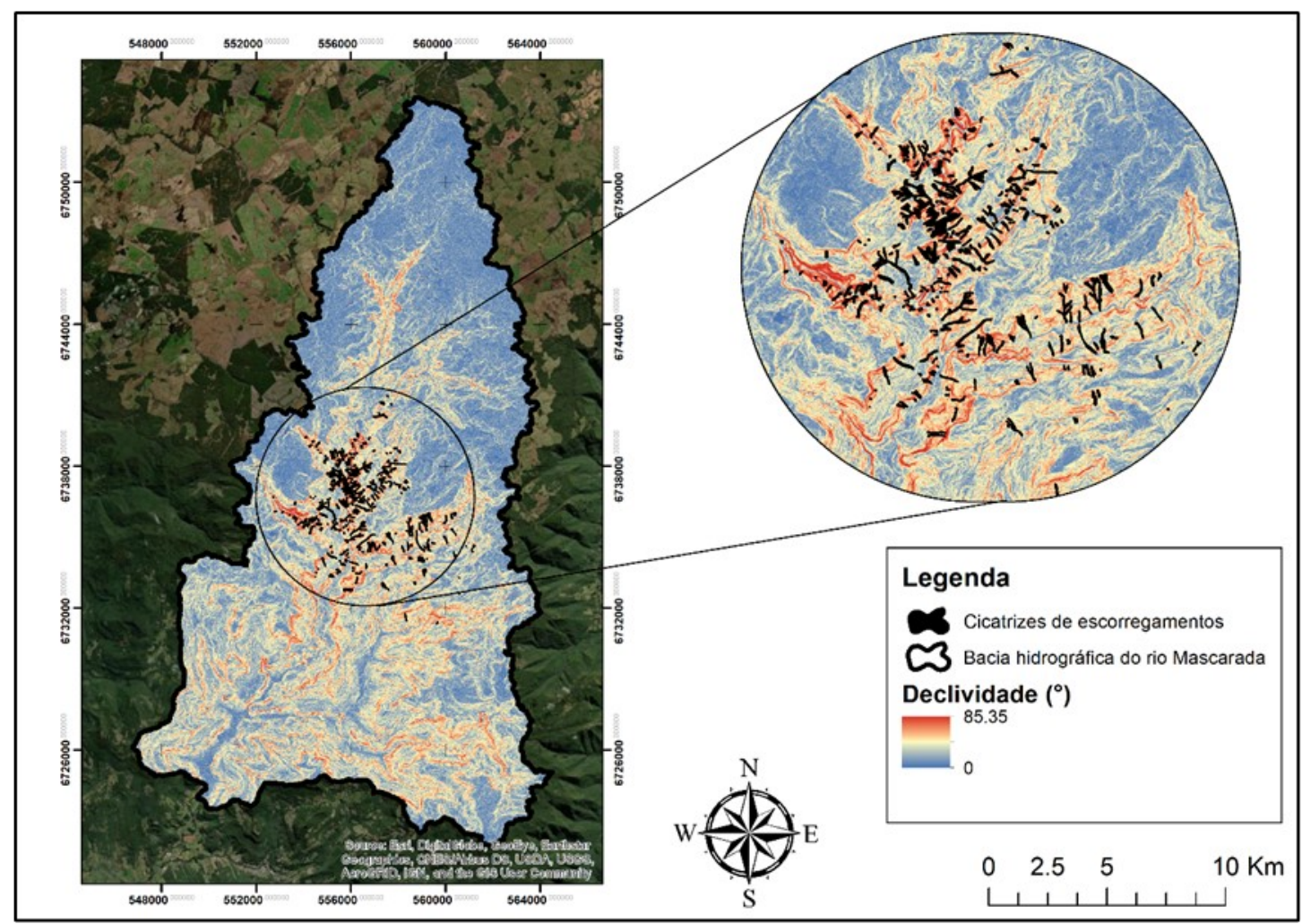

Fonte: Autores 
Zanandrea et al. (2018) apresentaram os valores de declividade e curvatura para a mesma área, porém a análise foi feita com um MDT com 12,5 metros de resolução. A comparação mostra que para a declividade os valores apresentam pouca diferença entre as porcentagens das classes. Entretanto, quando a comparação é feita para a curvatura o resultado é bastante diferente, uma vez que para o MDT de 12,5 metros, que foi obtido antes dos escorregamentos acontecerem, a curvatura apresentou também as classes "convergente-convexa", "divergentecôncava" e "divergente-convexa", o que demonstra a importância da avaliação cuidadosa do MDT utilizado para a descrição geomorfológica de bacias hidrográficas.

Tabela 2 - Classe de declividades dos escorregamentos de terra

\begin{tabular}{l|c|c}
\hline Classe (graus) & Número de Cicatrizes & Porcentagem \\
\hline $15-25$ & 17 & 4,70 \\
\hline $25-35$ & 157 & 43,37 \\
\hline $35-45$ & 143 & 39,50 \\
\hline $45-65$ & 45 & 12,43 \\
\hline
\end{tabular}

A análise do ordenamento de Strahler (1957) e Tsukmato e Minematsu (1958) mostra que todos os escorregamentos iniciaram em drenagens de ordem zero e $27,9 \%$ desses não atingiram uma drenagem de ordem maior, consequentemente, não estão conectados ao canal. A maioria dos escorregamentos atingiram drenagens de ordem 1 e 5, sendo que esses somados representam 43,6\%, conforme Tabela 3 . Ao todo $72,1 \%$ dos escorregamentos atingiram uma drenagem de ordem 1 ou superior, ou seja, estão conectados com o canal (Figura 6). O rio Mascarada é de ordem 5, assim, houve diversos escorregamentos que contribuíram diretamente para o rio principal o que comprova a grande influência dos escorregamentos na produção de sedimentos ocorrida durante o evento estudado. 
A dinâmica hidrossedimentológica da bacia foi alterada não só durante o evento, mas como um todo, visto que $94.5 \%$ da área onde ocorreram os escorregamentos eram de "florestas", 3,25\% de agricultura e os 2,47\% restantes divididos entre "estradas de terra", "pasto" e "solo exposto", agora, consequentemente, são de "solo exposto" (Figura 9). Segundo Morris e Fan (1998) os escorregamentos de terra e fluxo de detritos também geram diversos depósitos de material desestabilizado de sedimentos ao longo do caminho percorrido. Todos estes depósitos tornam-se potenciais fontes de sedimentos ativas para a bacia hidrográfica, o que ocasiona alterações na dinâmica hidrossedimentológica da bacia em uma situação pós-evento.

Figura 9 - Uso do solo da bacia hidrográfica do rio Mascarada

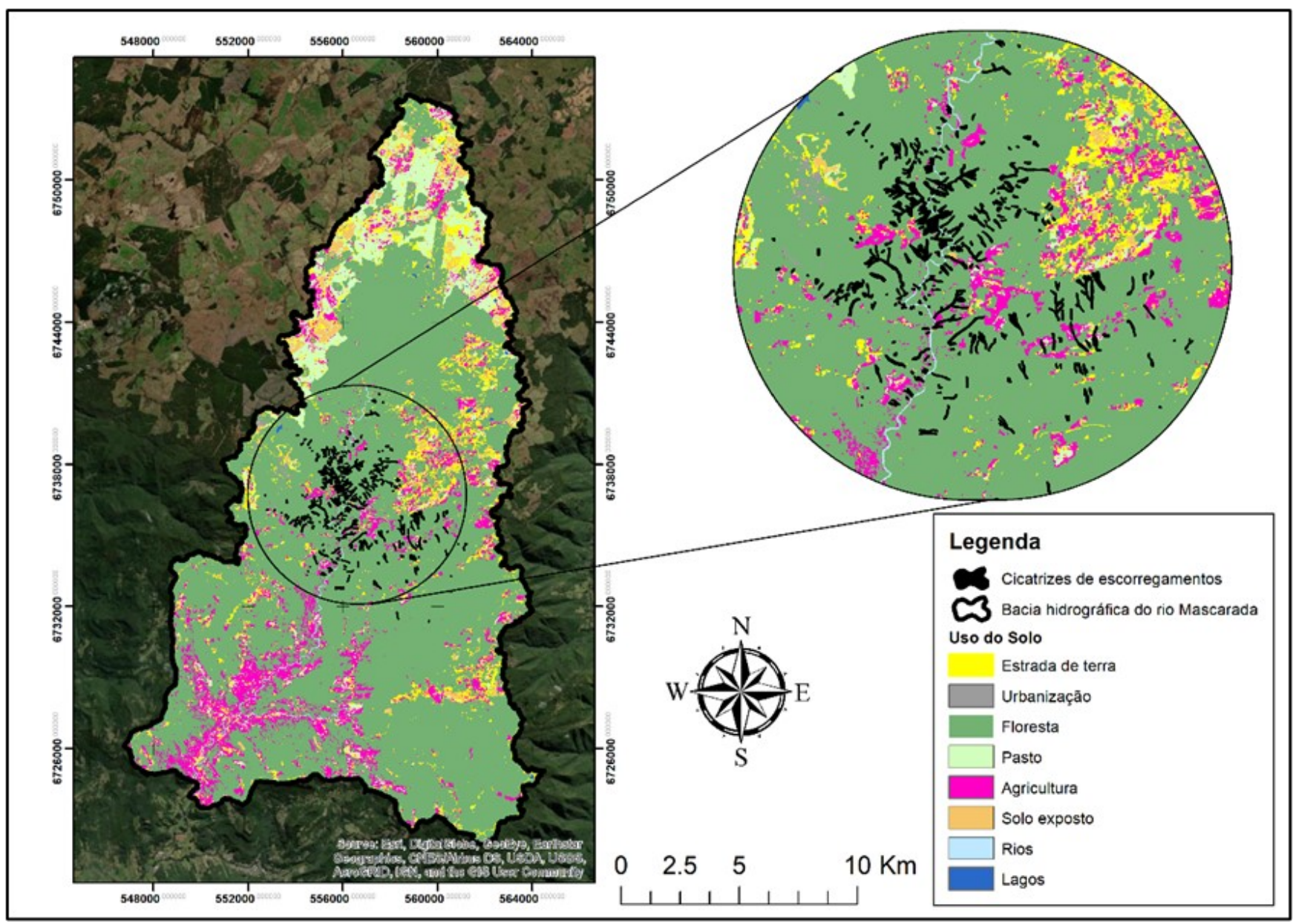

Fonte: Autores 
Tabela 3 - Ordenamento de Strahler (1957) e Tsukmato e Minematsu (1958) dos rios onde chegaram os escorregamentos

\begin{tabular}{l|c|c}
\hline Ordem do rio atingido pelo escorregamento & $\mathbf{N}^{\circ}$ de escorregamentos & Porcentagem (\%) \\
\hline 0 & 101 & 27,9 \\
\hline 1 & 79 & 21,8 \\
\hline 2 & 34 & 9,4 \\
\hline 3 & 69 & 19,1 \\
\hline 4 & 0 & 0 \\
\hline 5 & 79 & 21,8 \\
\hline 6 & 0 & 0 \\
\hline
\end{tabular}

A realização do teste ANOVA mostrou que para a declividade não há diferença significativa entre os valores de declividade média das cicatrizes, dos centroides e do ponto no início da cicatriz, o que demonstra a dificuldade em se estabelecer limiares de declividade para separação de áreas de ruptura, transporte e deposição dos movimentos de massa. Porém todos esses apresentam diferença significativa quando comparados com pontos aleatórios distribuídos pela bacia onde não ocorreram cicatrizes. Já quando o teste foi realizado para o TWI os resultados mostraram-se diferentes da declividade, uma vez que há diferença significativa entre o ponto no início e no centroide da cicatriz, entre as médias das cicatrizes e o início da cicatriz, pois os valores de TWI tendem a ser maiores ao longo da linha de fluxo.

Dietrich, Wilson e Reuneau (1986) propuseram que a zona de iniciação de canais de drenagem é mantida por escorregamentos recorrentes que removem uma pequena parcela do colúvio depositado nos "hollows" e, ainda, Montgomery e Dietrich (1994) mostram que quanto maior a declividade menor é a área de contribuição para iniciação de um canal. Esta teoria posteriormente foi implementada no modelo de escorregamentos globalmente famoso, o Shallow Landslide Stability Model (Shalstab). Assim, assumindo que a iniciação dos 
escorregamentos podem ser também a de canais e para confrontar os dados do inventário com um possível resultado do modelo Shalstab, foram plotados os resultados de "Declividade x Área de contribuição" (Figura 8), para conferência da proposição feita.

Para composição do gráfico foram utilizados valores hipotéticos para parâmetros de caracterização do solo. A linha vertical mais próxima ao eixo das ordenadas representa o limiar máximo da estabilidade incondicional, ou seja, representa a máxima declividade em que mesmo em saturação, não há condições para ocorrência de escorregamentos. A linha vertical mais distante do eixo das ordenadas representa o limiar mínimo da instabilidade incondicional, ou seja, uma declividade a partir da qual, mesmo sem água no solo, já existem condições para ocorrência do escorregamento. O espaço entre estas duas linhas verticais representa a faixa de declividade onde a instabilidade depende da relação entre área de contribuição e declividade. É justamente nesta faixa que a teoria de Montgomery e Dietrich (1994) pode ser aplicada. Ainda no gráfico, as linhas tracejadas representam limiares de saturação para uma determinada condição de recarga do solo, estando os pontos acima da linha em condições de saturação e abaixo da linha em condições de não saturação. Por último, as linhas contínuas representam os limiares de estabilidade para determinada condição de recarga do solo, estando pontos acima da linha em condição de instabilidade e abaixo da linha em condições de estabilidade. Normalmente utiliza-se um limiar de condição de recarga para determinar as áreas propensas a escorregamentos em uma determinada localidade (Michel et al., 2015). O valor mais comumente adotado é $\log q / T=-3,1$ (Dietrich et al., 2001), sendo q a taxa de recarga do solo $(\mathrm{mm} / \mathrm{h})$ e $T$ a transmissividade do solo $\left(\mathrm{mm}^{2} / \mathrm{h}\right)$. 
Figura 10 - Relação entre área de contribuição e declividade para os escorregamentos mapeados. A sigla LS na legenda da figura representa o termo "Limiar de Saturação". O parâmetro q/T representa a relação entre taxa de recarga e transmissividade do solo. Os valores hipotéticos dos parâmetros do solo utilizados para elaboração do gráfico foram: ângulo de atrito interno do solo $=38^{\circ}$ e massa específica do solo $=1800 \mathrm{~kg} / \mathrm{m}^{3}$

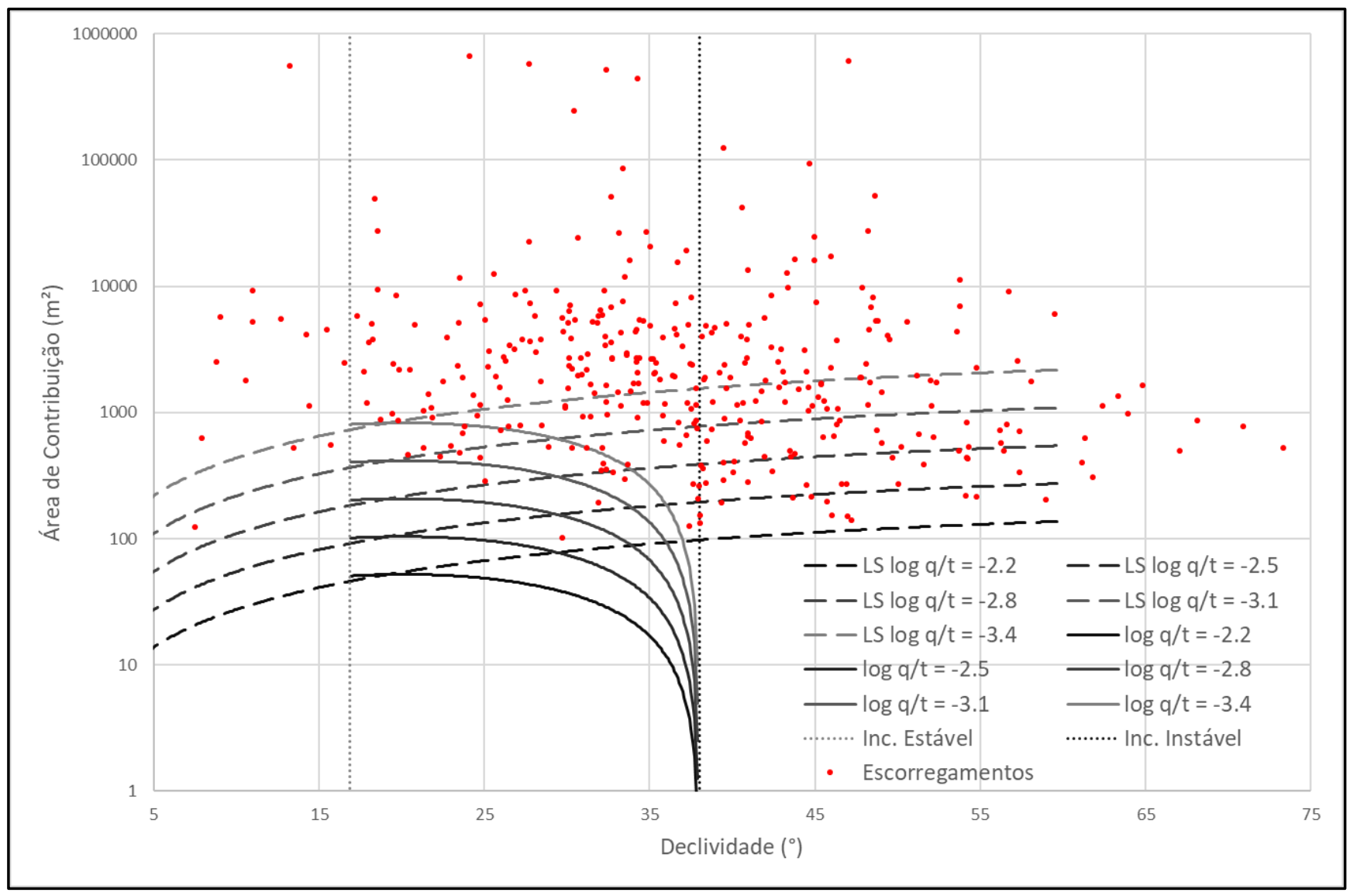

Ao analisar a Figura 10 evidencia-se que poucos escorregamentos (cerca de 4\%) incidiram sobre a região incondicionalmente estável. Outros $44 \%$ incidiram sobre regiões incondicionalmente instáveis. Estes dois resultados representam que os valores de parâmetros do solo utilizados para estabelecer o gráfico comparativo do modelo podem não ser totalmente representativos das condições do solo local. Entretanto, cerca de 52\% dos escorregamentos incidiram na faixa de declividades onde a condição de instabilidade é estabelecida pela relação entre área de contribuição e declividade, sendo que quanto maior a área de contribuição, menor a declividade necessária para criar a condição de 
instabilidade. Nesta faixa, a adoção de um limiar de estabilidade de log q/T igual a -3,1 claramente cria uma fronteira entre pontos de ocorrência e não ocorrência de escorregamentos, sendo que apenas $2 \%$ dos escorregamentos nesta faixa teriam incidido em áreas consideradas estáveis para este limiar. Esta análise representa que os escorregamentos possivelmente constituem-se em escorregamentos translacionais rasos deflagrados por incidência de fortes chuvas que geraram uma alta taxa de recarga no solo. Esta recarga, ao percolar pelo solo concentrou-se em zonas de convergência das encostas criando condições de umidade propícias aos escorregamentos.

\section{CONCLUSÕES}

O trabalho caracterizou e inventariou os movimentos de massa que ocorreram na bacia hidrográfica do rio Mascarada, sendo adotadas diferentes metodologias para a descrição geomorfológicas desses, contribuindo assim para o entendimento da dinâmica dessa bacia hidrográfica.

Dentre as diferentes metodologias adotadas para a avaliação da magnitude do evento ocorrido, destaca-se o uso da "área de influência" mostrou-se ser a mais adequada. Visto que o uso dessa faz com áreas de montante que não estão relacionas diretamente com os escorregamentos, não interfiram nos resultados tornando-os menos expressivos devido ao aumento da área analisada. A utilização da área de influência em outras áreas de estudo pode trazer uma métrica comparativa para avaliação de desastres naturais.

A metodologia proposta se mostrou interessante a partir dos dados obtidos, podendo ser utilizada para realização de inventários de desastres naturais que ocasionem escorregamentos de terra e fluxo de detritos. Porém, quando se trata de características geomorfológicas é necessário um cuidado especial para o uso de valores padrão da literatura, uma vez que as características climáticas, geomorfológicas, geológicas e de uso do solo fazem com que cada bacia seja praticamente única. Ao comparar a declividade dos escorregamentos deste estudo com inventários de regiões do Japão e até mesmo do Brasil, 
as médias foram significativamente inferiores. Ainda, a avaliação feita a través da teoria de Montgomery e Dietrich (1988) mostrou que diversos escorregamentos são representados pelo limiar de log q/t igual -3,1, porém alguns ficaram na zona considerada incondicionalmente estável, o que mostra que há uma complexidade de variáveis que devem ser avaliadas para a caracterização da estabilidade das encostas. Assim, a diversidade de resultados apresentadas nos diferentes inventários mostra a importância da comparação de inventários de regiões semelhantes, uma vez que os fatores governantes da estabilidade podem ter pesos diferentes para cada bacia hidrográfica.

Os resultados obtidos e a metodologia proposta neste inventário de movimentos de massa se mostraram potencialmente interessantes para validação de modelos de estabilidade de encosta e fluxo de detritos, auxiliando na elaboração de mapas de perigo e risco para a adequada gestão dos desastres naturais.

O evento pluviométrico do dia 05/01/2017 ocasionou uma mudança na paisagem da bacia do rio Mascarada através dos escorregamentos o que, consequentemente, também mudou sua dinâmica sedimentológica. Dado que as cicatrizes dos escorregamentos agora representam porções de solo exposto onde anteriormente eram áreas, predominantemente, de floresta. Estas regiões se tornam pontos quentes de depósito de sedimentos que podem ser mobilizados facilmente em um próximo evento. A alta vazão com forte presença de detritos lenhosos gerada durante o evento provocou mudanças bruscas na morfologia do rio principal.

Eventos pluviométricos como esse enfatizam a necessidade do monitoramento de pequenas bacias hidrográficas, visto que os movimentos de massa, geralmente, ocorrem nessas bacias de menor extensão territorial. Entretanto, os seus efeitos indiretos podem atingir longas distâncias, como no caso do evento estudado nesse trabalho. Assim, a elaboração de inventários de movimentos de massa torna-se indispensável para a gestão dessas áreas, visto que, para esse tipo de fenômeno natural, o passado é a chave para o futuro. 


\section{AGRADECIMENTOS}

Os autores agradecem a toda comunidade da bacia hidrográfica do rio Mascarada, em especial aos Bombeiros Voluntários de Rolante e ao Noel e sua família.

\section{REFERÊNCIAS}

Avelar, André S.; Netto, Ana L. Coelho; Lacerda, Willy A.; Becker, Leonardo B.; Mendonça, Marcos B. Mechanisms of the Recent Catastrophic Landslides in the Mountainous Range of Rio de Janeiro, Brazil. Landslide Science And Practice, [S.L.], p. 265-270, 2013. Springer Berlin Heidelberg. http://dx.doi.org/10.1007/978-3-642-31337-0_34.

Bauzys, Fernanda. Identificação, análise e mapeamento dos movimentos de massa ocorridos em novembro de 2008, no alto da bacia do ribeirão Belchior, Gaspar-SC. 2010. 209 f. Dissertação (Mestrado) - Curso de Geografia, Universidade Federal de Santa Catarina, Florianópolis, 2010.

CPRM. Relatório de vistoria em áreas de risco no município de Rolante/RS. Porto Alegre: Cprm, 2010.

Dantas, Marcelo Eduardo; Armesto, Regina Célia Gimenez; Adamy, Amílcar. Origem das Paisagens. In: Silva, C. R. Geodiversidade do Brasil: conhecer o passado para entender o presente e prever o futuro. 8. ed. Rio de Janeiro: Cprm, 2008. p. 33-56.

Dietrich, William E.; Bellugi, Dino; Asua, Raphael Real de. Validation of the Shallow Landslide Model, Shalstab, for forest management. Water Science And Application, [S.L.], p. 195-227, 2001. American Geophysical Union. http://dx.doi.org/10.1029/ws002p0195.

Dietrich, William E.; Wilson, Cathy J.; Reneau, Steven L. Hollows, colluvium, and landslides in soilmantled landscapes. Hillslope processes, p. 361-388, 1986.

Dümig, Alexander; Schad, Peter; Kohok, Manmath; Beyerlein, Patrick; Schwimmer, Wolfgang; Kögel-Knabner, Ingrid. A mosaic of nonallophanic Andosols, Umbrisols and Cambisols on rhyodacite in the southern Brazilian highlands. Geoderma, [S.L.], v. 145, n. 1-2, p. 158-173, maio 2008. Elsevier BV. http://dx.doi.org/10.1016/j.geoderma.2008.01.013.

Fan, Jiahua; Morris, Gregory L.. Reservoir Sedimentation. I: delta and density current deposits. Journal Of Hydraulic Engineering, [S.L.], v. 118, n. 3, p. 354-369, mar. 1992. American Society of Civil Engineers (ASCE). http://dx.doi.org/10.1061/(asce)0733-9429(1992)118:3(354). 
Froude, Melanie J.; Petley, David N.. Global fatal landslide occurrence from 2004 to 2016. Natural Hazards And Earth System Sciences, [S.L.], v. 18, n. 8, p. 2161-2181, 23 ago. 2018. Copernicus GmbH. http://dx.doi.org/10.5194/nhess-18-2161-2018.

GPDEN/SEMA. Diagnóstico preliminar. Porto Alegre: Drh/sema, 2017. Disponível em: http://www.rs.gov.br/upload/20170125183225diagnostico_preliminar_gt_rolante_revfinal.pdf. Acesso em: 15 jan. 2020

Gregory, K. J.; walling, D. E.. The variation of drainage density within a catchment. International Association Of Scientific Hydrology. Bulletin, [S.L.], v. 13, n. 2, p. 61-68, jun. 1968. Informa UK Limited. http://dx.doi.org/10.1080/02626666809493583.

Guzzetti, Fausto; Mondini, Alessandro Cesare; Cardinali, Mauro; Fiorucci, Federica; Santangelo, Michele; Chang, Kang-Tsung. Landslide inventory maps: new tools for an old problem. EarthScience Reviews, [S.L.], v. 112, n. 1-2, p. 42-66, abr. 2012. Elsevier BV. http://dx.doi.org/10.1016/j.earscirev.2012.02.001.

IBGE - Instituto Brasileiro De Geografia E Estatística. Censo demográfico. Rio de Janeiro (Brasil) 2010.

Iwahashi, Junko; Watanabe, Shiaki; Furuya, Takahiko. Landform analysis of slope movements using DEM in Higashikubiki area, Japan. Computers \& Geosciences, v. 27, n. 7, p. 851-865, 2001.

Iwahashi, Junko; Watanabe, Shiaki; Furuya, Takahiko. Mean slope-angle frequency distribution and size frequency distribution of landslide masses in Higashikubiki area, Japan. Geomorphology, [S.L.], v. 50, n. 4, p. 349-364, mar. 2003. Elsevier BV. http://dx.doi.org/10.1016/s0169$555 \times(02) 00222-2$.

Kalantari, Zahra; Ferreira, Carla Sofia Santos; Koutsouris, Alexander J.; Ahlmer, Anna-Klara; Cerdà, Artemi; Destouni, Georgia. Assessing flood probability for transportation infrastructure based on catchment characteristics, sediment connectivity and remotely sensed soil moisture. Science of The Total Environment, [S.L.], v. 661, p. 393-406, abr. 2019. Elsevier BV. http://dx.doi.org/10.1016/j.scitotenv.2019.01.009.

Kirschbaum, Dalia; Stanley, Thomas; Zhou, Yaping. Spatial and temporal analysis of a global landslide catalog. Geomorphology, [S.L.], v. 249, p. 4-15, nov. 2015. Elsevier BV. http://dx.doi.org/10.1016/j.geomorph.2015.03.016.

Lopes, Eymar Silva Sampaio; Riedel, Paulina Setti; Bentz, Cristina Maria; Ferreira, Mateus Vidotti; Naleto, João Luis Carneiro. Inventário de escorregamentos naturais em banco de dados geográfico-análise dos fatores condicionantes na região da Serra de Cubatão-SP. XIII Simpósio Brasileiro de Sensoriamento Remoto, Florianópolis, p. 2785-2796, 2007a. 
Lopes, Eymar Silva Sampaio; Riedel, Paulina Setti; Bentz, Cristina Maria; Ferreira, Mateus Vidotti . Calibração e validação do índice de estabilidade de encostas com inventário de escorregamentos. Geociências, 2007b.

Michel, Gean Paulo; Goerl, Roberto Fabris; Kobiyama, Masato. Critical rainfall to trigger landslides in Cunha River basin, southern Brazil. Natural Hazards, [S.L.], v. 75, n. 3, p. 2369-2384, 24 set. 2014. Springer Science and Business Media LLC. http://dx.doi.org/10.1007/s11069-014-1435-6.

Montgomery, David R.; Dietrich, William E. Where do channels begin?. Nature, v. 336, n. 6196, p. 232-234, 1988.

Montgomery, David R.; Dietrich, William E.. A physically based model for the topographic control on shallow landsliding. Water Resources Research, [S.L.], v. 30, n. 4, p. 1153-1171, abr. 1994. American Geophysical Union (AGU). http://dx.doi.org/10.1029/93wr02979.

Murillo-García, Franny Giselle; Alcántara-Ayala, Irasema. Landslide Susceptibility Analysis and Mapping Using Statistical Multivariate Techniques: pahuatlán, puebla, mexico. Springer Series In Geomechanics And Geoengineering, [S.L.], p. 179-194, 2015. Springer International Publishing. http://dx.doi.org/10.1007/978-3-319-11053-0_16.

Paolella, Marc S. Linear Models and Time-Series Analysis: Regression, ANOVA, ARMA and GARCH. John Wiley \& Sons, 2018.

Roback, Kevin; Clark, Marin K.; West, A. Joshua; Zekkos, Dimitrios; LI, Gen; Gallen, Sean F.; Chamlagain, Deepak; Godt, Jonathan W.. The size, distribution, and mobility of landslides caused by the 2015 Mw7.8 Gorkha earthquake, Nepal. Geomorphology, [S.L.], v. 301, p. 121-138, jan. 2018. Elsevier BV. http://dx.doi.org/10.1016/j.geomorph.2017.01.030.

Samia, Jalal; Temme, Arnaud; Bregt, Arnold; Wallinga, Jakob; Guzzetti, Fausto; Ardizzone, Francesca; Rossi, Mauro. Do landslides follow landslides? Insights in path dependency from a multi-temporal landslide inventory. Landslides, [S.L.], v. 14, n. 2, p. 547-558, 29 jul. 2016. Springer Science and Business Media LLC. http://dx.doi.org/10.1007/s10346-016-0739-x.

Seefelder, Carolina de Lima Neves; Koide, Sérgio; Mergili, Martin. Does parameterization influence the performance of slope stability model results? A case study in Rio de Janeiro, Brazil. Landslides, [S.L.], v. 14, n. 4, p. 1389-1401, 16 dez. 2016. Springer Science and Business Media LLC. http://dx.doi.org/10.1007/s10346-016-0783-6.

Smyth, Conor G.; Royle, Stephen A. Urban landslide hazards: incidence and causative factors in niterói, rio de janeiro state, brazil. Applied Geography, [S.L.], v. 20, n. 2, p. 95-118, abr. 2000. Elsevier BV. http://dx.doi.org/10.1016/s0143-6228(00)00004-7.

Strahler, Arthur N. Quantitative analysis of watershed geomorphology. Transactions, American Geophysical Union, [S.L.], v. 38, n. 6, p. 913-920, 1957. American Geophysical Union (AGU). http://dx.doi.org/10.1029/tr038i006p00913. 
Tsukamoto, Y.; Minematsu, H. Hydrogeomorphological characteristics of a zero-order basin. IAHSAISH publication, n. 165, p. 61-70, 1987.

Zanandrea, Franciele; Cardozo, Gabriel; Michel, Gean Paulo; Kobiyama, Masato. Parâmetros geomorfológicos para avaliação pós-desastre de escorregamentos: estudo de caso da bacia hidrográfica do Rio Mascarada/RS. Encontro Nacional de Desastres (1., jul. 2018, Porto Alegre). Anais. Porto Alegre: ABRHidro,[2018]., 2018.

\section{CONTRIBUIÇÕES DE AUTORIA}

\section{1 - Gabriel Lopes Cardozo}

Instituto de Pesquisas Hidráulicas, UFRGS, Engenheiro Ambiental.

https://orcid.org/0000-0002-4662-0200 - gabriel_lopes_cardozo@hotmail.com

Contribuição: Curadoria de dados, Análise Formal, Investigação, Metodologia, Escrita.

\section{2 - Franciele Zanandrea}

Instituto de Pesquisas Hidráulicas, Universidade Federal do Rio Grande do Sul, Doutora em Recursos Hídricos e Saneamento Ambiental.

https://orcid.org/0000-0002-4797-1379 - Franciele.zanan@gmail.com

Contribuição: Conceituação, Análise Formal, Investigação, Metodologia, Escrita - revisão e edição.

\section{3 - Gean Paulo Michel}

Instituto de Pesquisas Hidráulicas, Universidade Federal do Rio Grande do Sul. Doutor em Recursos Hídricos e Saneamento Ambiental e Professor Adjunto do IPH/UFRGS. https://orcid.org/0000-0002-7857-1941 - gean.michel@ufrgs.br Contribuição: Conceituação, Análise Formal, Supervisão, Escrita - revisão e edição.

\section{4 - Masato Kobiyama}

Instituto de Pesquisas Hidráulicas, Universidade Federal do Rio Grande do Sul. Doutor em Engenharia Florestal e Professor Titular do Instituto de Pesquisas Hidráulicas e Universidade Federal do Rio Grande do Sul. https://orcid.org/0000-0003-0615-9867 - masato.kobiyama@ufrgs.br Contribuição: Supervisão, Escrita - revisão e edição.

\section{COMO CITAR ESTE ARTIGO}

CARDOZO, G.L.; ZANANDREA, F.; MICHEL, G.P.; KOBIYAMA, M. Inventário de movimentos de massa na bacia hidrográfica do rio Mascarada/RS. Ciência e Natura, Santa Maria, v. 43, e31, p. 1-26, 2021. Disponível em: https://doi.org/10.5902/2179460X43594. Acesso em: dia, mês (abreviado), ano. 